\title{
Erratum to: The Puzzle of Male Chronophilias
}

\author{
Michael C. Seto ${ }^{1}$
}

Published online: 12 July 2017

(C) Springer Science+Business Media, LLC 2017

\section{Erratum to: Arch Sex Behav (2017) 46:3-22 DOI 10.1007/s10508-016-0799-y}

Due to an editing error, Fig. 7 did not contain several key numbers and an explanation of the numbers in the figure note. The correct Fig. 7 and note are copied below.

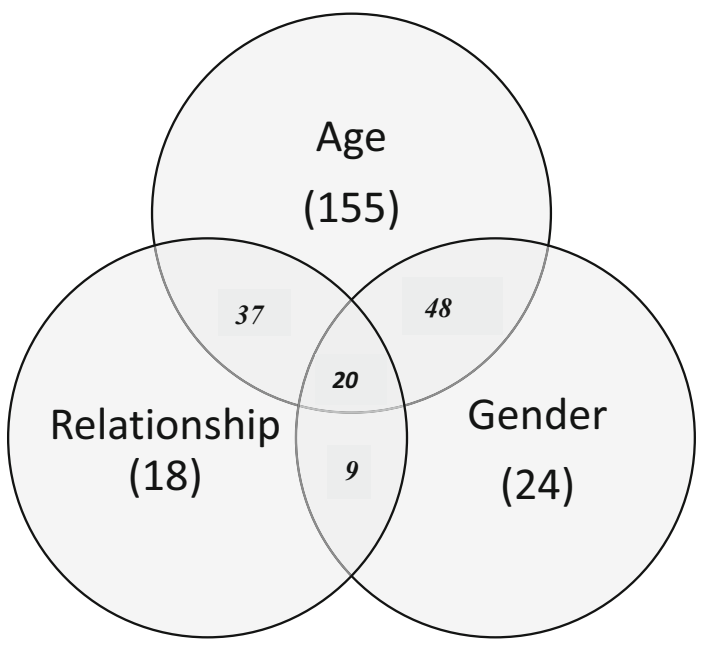

Fig. 7 Venn diagram of patterns of polymorphism for 311 polymorphic sexual offenders reported by Stephens, Seto, Goodwill, and Cantor (2016). Note The numbers in parentheses refer to the number of offenders who displayed that type of victim polymorphism (e.g., 155 displayed victim age polymorphism). The bolded and italicized numbers in the intersections refer to the number of offenders who were polymorphic in multiple domains; for example, 20 individuals displayed victim age, gender, and relationship polymorphism in their sexual offending history

The online version of the original article can be found under doi:10.1007/ s10508-016-0799-y.

\section{Michael C. Seto}

michael.seto@theroyal.ca

1 Royal Ottawa Health Care Group, Ottawa, ON K1Z 7K4,

Canada 